\title{
Medical Imaging and Imaging Technique Documentation
}

National Cancer Institute

\section{Source}

National Cancer Institute. Medical Imaging and Imaging Technique Documentation. NCI

Thesaurus. Code C115715.

Records detailing the proper use of digital medical images, and digital imaging techniques for the capture and interpretation of data in a clinical trial. 